\title{
MECHANICAL STRENGTH PROPERTIES OF TURMERIC RHIZOME AT DIFFERENT GEOMETRIC SIZE WITH ATTRIBUTE TO MOISTURE CONTENT
}

\author{
OBASA P. A ${ }^{1^{*}}$, MUOGBO P. C ${ }^{2}$, AJIBOYE M.O ${ }^{1}$, ADEROTOYE A.M ${ }^{3}$ \\ ${ }^{1}$ Department of Agricultural and Bioresources Engineering, Federal University of Technology, Minna, \\ Niger State Nigeria. \\ ${ }^{2}$ National Root Crops Research Institute, Nyanya Sub- Station, Abuja, Nigeria. \\ ${ }^{3}$ Department of Agricultural and Environmental Engineering, Federal University of Technology, Akure, \\ Ondo State Nigeria. \\ *corresponding Author: peter.obasa@ futminna.edu.ng
}

\begin{abstract}
The ever-increasing importance of agricultural products together with the complexity of modern technology for their production, processing and storage need a better knowledge of their engineering properties so that machines, processes and handling operations can be designed for maximum efficiency and the highest quality of the final end products. Raw food materials are biological and have certain unique characteristics. Turmeric undergoes various unit operations from pre-harvest to post-harvest, processing, preservation, packaging, storage distribution, and final consumption. During all these processes, the properties of turmeric will be changed. The shortage of processing and preservative equipment for Turmeric, which may be due to the fact that data on the engineering properties of turmeric required for the design of these machines are insufficient or not available in some cases. Compressive Force (N), Max Strength (MPa), Force Holding Capacity $(\mathrm{N})$. a full factorial randomized subtype design with two factorial interaction model tests was used to develop the experimental runs of eighteen (18) using design expert 11.1.2.0 statistical package Complete test carried out on the mechanical properties of the turmeric rhizome samples was decreasing with increase in the moisture content of the rhizomes at 3 to $15.8 \mathrm{~N}$ compressive force, 207 to $478.35 \mathrm{MPa}$ max rhizome strength except for force holding capacity that increases with increase in moisture content between 2 to $11 \mathrm{~N}$, Geometric size of the all sample tested was completely increasing with increase in the rhizome size. The tested properties analysis values at $\mathrm{P} \leq 0.05$ indicate that the properties tested are all significant at difference moisture content and geometric size, while the two factors interaction shows no significant effect on the tested properties.
\end{abstract}

Keyword: Force, Interaction, Moisture, Storage, Strength

\section{Introduction}

Turmeric (Curcuma longa) is a flowering, perennial, rhizomatous, and herbaceous plant native to tropical South Asia but is now widely cultivated in the tropical and subtropical regions of the world. It is a rhizome(root) that comes from the plant of the ginger family of herbs. It can be used 
as the condiment, a textile dye, cosmetic and drugs, medically as an aromatic stimulant and in addition to its use in religious ceremonies. India being the largest producer of turmeric supplies 94\% of the world demand (Fadavi et al, 2005).

In Nigeria, it is cultivated mostly in the homestead gardens in about 19 states where they bear different names and serve different purposes. In Ebonyi and Enugu states, it is used for treatment of malaria and for circumcision, in Benue state it is used fresh for making yams meals while in Kastina State inhabitant use it for decoration (Olojede, 2000). Turmeric rhizome has antioxidant, anti-inflammatory, antiviral and antifungal actions. Studies have shown that curcumin is not toxic to humans. Turmeric is effective in reducing post-surgical inflammation and also helps to prevent atherosclerosis by reducing the formation of blood clumps (Akram et al., 2010).

As a dried rhizome of an herbaceous plant, turmeric is firmly identified with ginger. The zest is additionally in some cases called "Indian saffron" due to its yellow shading which confers an unmistakable flavour to food and fills in as a shading part, food and refreshments addictive (Govindarajan, 1980). Flavour are ground either for direct use or making esteem included items, for example, ground flavours, blends, oleoresins and zest oil extricate which have immense modern applications. In any case, entire flavours are additionally utilized in powdered or glue structure. The properties which are valuable during configuration must be resolved under research centre conditions (Gursoy and Guzel, 2010). The rhizome, the bit of the plant utilized medicinally as a yellow powder which is utilized as a flavour in numerous foods and as a medication to treat numerous maladies especially as mitigating and for the treatment of tooting, jaundice, feminine challenges, haematuria, drain, and colic or can be applied as a salve to treat many skin ailments. It likewise assists with improving its unmistakable flavours, tones, fragrances and furthermore improve food handling and food readiness. The yellow shaded bioactive segment of turmeric fills in as calming, hostile to mutagenic, anticoagulant, antifertility, against diabetic, antibacterial, antifungal, antiprotozoal, antiulcer, hypotensive exercises (Ercisli et al., 2007). The agricultural soil for turmeric cultivation should be rich and friable with plenty of organic matter. Though turmeric is suited for a number of soil types, loams and sandy loam soils are preferable. Flat land with little or no slope is recommended with planting distance of $30 \mathrm{~cm} \times 50 \mathrm{~cm}$ is often adopted for turmeric planting. It requires temperatures between 20 to $300 \mathrm{C}$ (68 and $860 \mathrm{~F}$ ) to thrive (Chattopadhyay et al., 2004). Turmeric plant reaches up to $1 \mathrm{~m}$ (3ft 3inch) tall. Highly branched, 
yellow to orange, cylindrical, aromatic rhizomes. The leaves are alternate and arranged in two rows. They are divided into leaf sheaths, petiole, and leaf blade. From the leaf sheaths, a false stem is formed. The petiole is 50 to $115 \mathrm{~cm}$ (20-45 inch) long. The simple leave blades are usually 76 to $115 \mathrm{~cm}$ (30-45inch) long and rarely up to $230 \mathrm{~cm}$ (91 inch). They have a width of 38 to $45 \mathrm{~cm}$ (15 to 18inch) and are oblong to elliptical, narrowing at the tip (Chattopadhyay et al., 2004).

Information on mechanical (properties that have to do with the conduct of agrarian items under applied powers, for example, stress, strain, hardness and compressive quality is essential to engineers taking care of farming items. The assurance of mechanical properties of agricultural products under static and dynamic stacking is focused on textural estimation of natural and prepared food materials; the decrease of mechanical harm to horticultural created during postharvest dealing with, handling, and capacity; and the assurance of plan boundaries for collecting and postharvest frameworks. Thusly, a level-headed way to deal with the plan of agricultural machinery, equipment and facilities will include the knowledge of the engineering properties of the products (Chukwu and Sunmonu 2010).

Mechanical properties such as hardness, compressive strength, impact and shear resistance and the rheological properties affect the various operations of agricultural processing. Data on these properties are useful for application in designing equipment for milling, handling, storage, transportation, food processing. The development of satisfactory harvesting and processing method are greatly influenced by the mechanical properties of the product (Kayode et al., 2019)

Some of the waste in agricultural products at different stages such as harvest, transfer, transportation, and processing are caused by unexpected loads and stresses upon them. Moreover, in order to process agricultural products, some loading needs to be done through cuts in or pressure on the Product. Thus, to prevent mechanical harm and waste during the harvest processes and the stages after that and to optimize processing devices, it is necessary to measure and study physical and mechanical properties of agricultural products (Akbarnejad, et al., 2007)

\section{Materials and Method}

Sample Preparation: The turmeric samples were obtained from National Root Crops Research Institute, Nyanya, Abuja, Nigeria. The rhizome plant was clean and graded into three (3) grade one (1) 75-80 mm, grade two (II): $65-70 \mathrm{~mm}$, grade three (III): 55-60 mm) with rhizome diameter of 15-20 mm range figure 1, the moisture content of the samples was varied at $65 \%, 75 \%$ and 
$85 \% \mathrm{MC}_{\mathrm{wb}}$. The experimental setup is a full factorial randomized subtype design with two factorial interaction model tests was used to develop the experimental runs of eighteen (18) using design expert 11.1.2.0 statistical package. the design matrix of the experiment Table 1.

\section{Table 1: Experimental matrix}

\section{Factor}

A Moisture Content

B
Units

$\left(\% \mathrm{MC}_{\mathrm{wb}}\right)$

$(\mathrm{mm})$
Type

Categoric

Categoric
$-1 \quad+1$

6585

6080

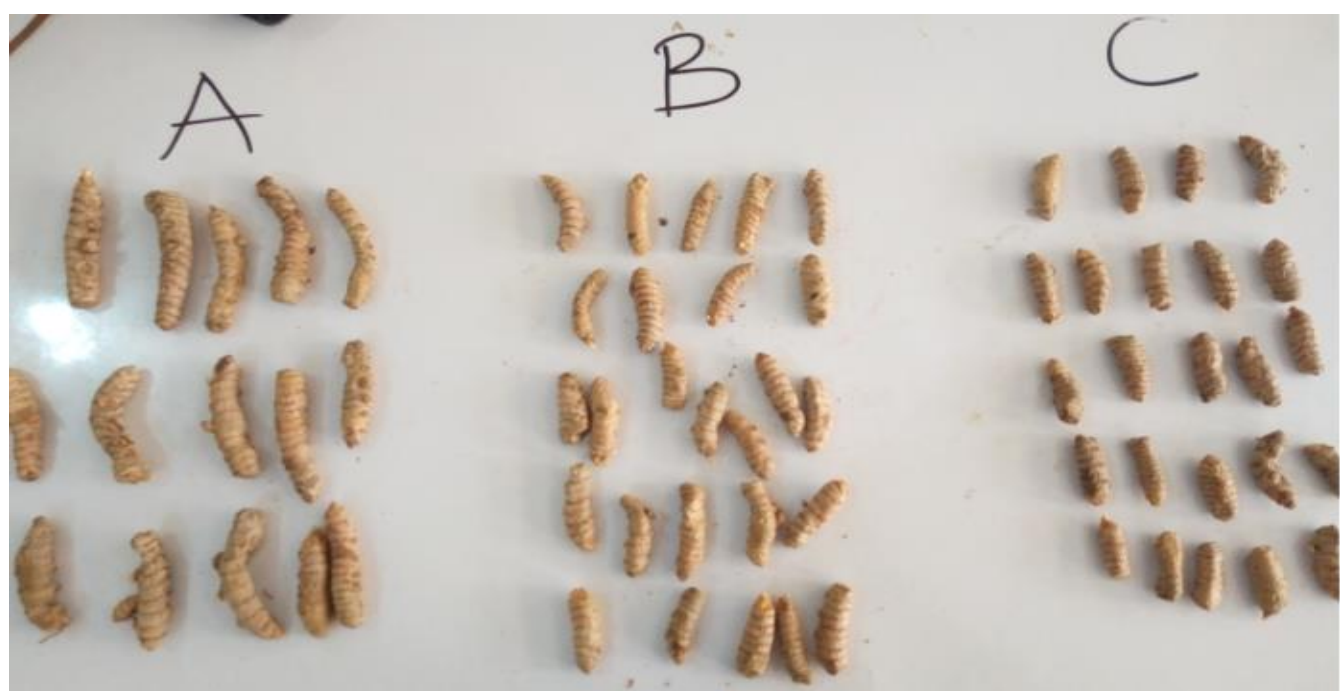

Figure 1: Turmeric Sample Grading.

Strength Properties Test

A static compression, ultimate strength, force holding test was carried out on universe testing machine (Figure 2) MARXTEST (TS 176). The rhizome samples were placed in the machine in vertical orientation, in such a way that the dimension were the large axis and small axis of crosssectional areas of the turmeric were subjected to the load (Muogbo P.C, and Obasa P. A, 2020). 


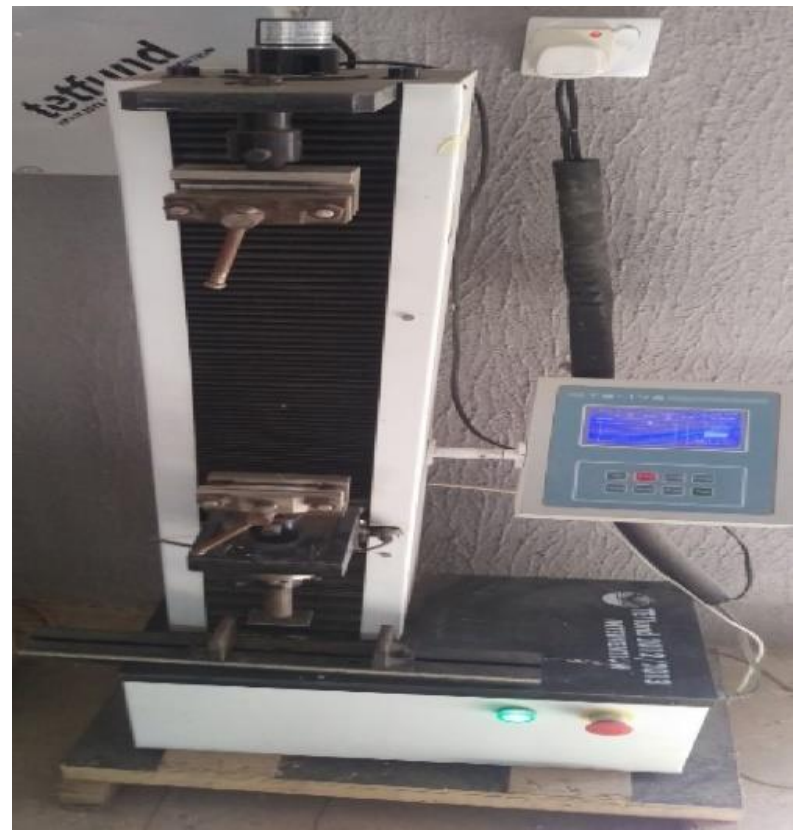

Figure 2: THE MARXTEST (TS 176). UTM machine.

\section{RESULT AND DISCUSSION:}

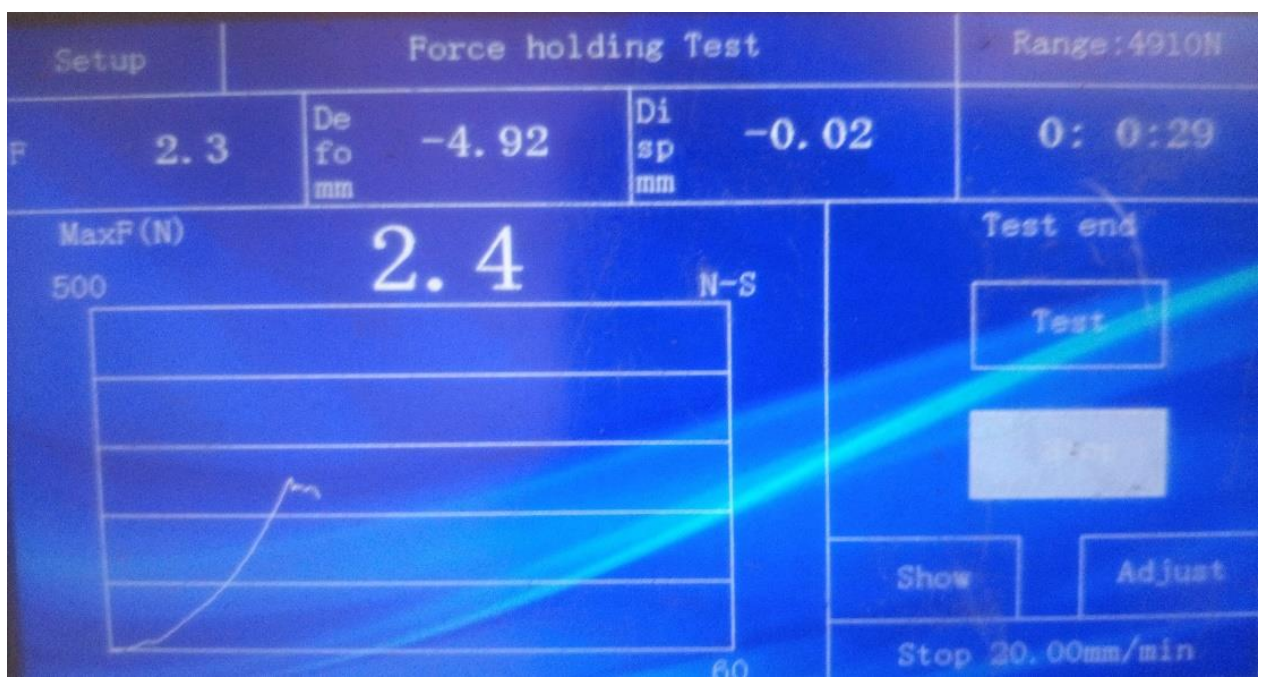

Figure 3: THE MARXTEST (TS 176). UTM machine screen readout. 
The result of the mechanical (strength) properties of the turmeric rhizome is as presented in Table 2. The result shows the response of Compressive Force (N), Max Strength (MPa), Force Holding Capacity (N).

Table 2: The result of the Mechanical (strength) properties of the Turmeric Rhizome

\begin{tabular}{|c|c|c|c|c|c|}
\hline & Factor 1 & Factor 2 & Response 1 & Response 2 & Response 3 \\
\hline Rur & $\begin{array}{l}\text { A:Moisture } \\
\text { Content }\end{array}$ & $\begin{array}{l}\text { B:Geometric } \\
\text { Size }\end{array}$ & $\begin{array}{l}\text { Compressive } \\
\text { force }(\mathrm{N})\end{array}$ & $\begin{array}{c}\text { Max Strength } \\
(\mathrm{MPa})\end{array}$ & $\begin{array}{l}\text { Force holding } \\
\text { Capacity }(\mathrm{N})\end{array}$ \\
\hline 1 & 75 & 70 & 7.3 & 278 & 5.9 \\
\hline 2 & 75 & 70 & 7.5 & 276.9 & 5.75 \\
\hline 3 & 65 & 60 & 5.2 & 238 & 3.6 \\
\hline 4 & 75 & 80 & 14 & 469.3 & 11 \\
\hline 5 & 65 & 60 & 5.23 & 234 & 3.7 \\
\hline 6 & 65 & 80 & 15.7 & 477 & 13 \\
\hline 7 & 75 & 60 & 4.5 & 213 & 3 \\
\hline 8 & 75 & 80 & 13.3 & 472.03 & 11.07 \\
\hline 9 & 85 & 80 & 12.4 & 445.41 & 10.2 \\
\hline 10 & 85 & 70 & 6 & 267 & 5.5 \\
\hline 11 & 85 & 60 & 3 & 207 & 2.4 \\
\hline 12 & 75 & 60 & 4.8 & 216 & 2.93 \\
\hline 13 & 65 & 80 & 15.8 & 478.38 & 13.7 \\
\hline 14 & 65 & 70 & 9.8 & 301 & 6.8 \\
\hline 15 & 85 & 70 & 5.88 & 265 & 5.4 \\
\hline 16 & 85 & 80 & 12.7 & 445.94 & 10 \\
\hline 17 & 85 & 60 & 3.5 & 210 & 2.4 \\
\hline 18 & 65 & 70 & 9.2 & 298.46 & 6.3 \\
\hline
\end{tabular}

The effect of the Moisture content and geometric size on the mechanical properties of Turmeric rhizome were tested for significance using analysis of variance ANOVA (Table 3,4 and 5). The tested properties analysis values at $\mathrm{P} \leq 0.05$ indicate that the model terms are significant, hence, in this study, both moisture content and geometric size has effect on tested properties responses. The Interaction effect properties are as present in Figure 4 to 6. 
Table 3: ANOVA For Selected Factorial Model for Turmeric Rhizome Compressive Max Force (N)

Response 1: Compressive max force (N)

\section{Source Sum of Squares Df Mean Square F-value p-value}

$\begin{array}{lrrrrrl}\text { Model } & 289.95 & 4 & & 72.49 & 848.45 & 0.001 \text { Significant } \\ \text { A-Moisture Content } & 286.23 & 2 & 143.12 & 1675.11 & 0.001 \\ \text { B-Geometric Size } & 3.72 & 2 & 1.86 & 21.79 & 0.001 \\ \text { AB } & 0.564 & 4 & 0.0421 & 2.31 & 0.136 \\ \text { Residual } & 1.11 & 13 & 0.0854 & & \\ \text { Lack of Fit } & 0.5630 & 4 & 0.1408 & 2.31 & 0.1362 \text { not significant } \\ \text { Pure Error } & 0.5476 & 9 & 0.0608 & & \\ \text { Cor Total } & 291.06 & 17 & & & \end{array}$

The two factors, moisture content and geometric size reviled that it has significant effect on the Compressive Force $(\mathrm{N})$, Max Strength $(\mathrm{MPa})$, Force Holding Capacity $(\mathrm{N})$. of the turmeric rhizome test in this research at $P_{-} \_$value $=(0.001,0.001) ;(0.001,0.01) ;(0.012,0.015)$ respectively while the Compressive Force $(\mathrm{N})$ interaction between the two factors was not significant at P_value $=0.136$. The Lack of Fit F-value of 2.31 implies the Lack of Fit is not significant relative to the pure error. There is a $13.62 \%$ chance that a Lack of Fit F-value this large could occur due to clatter during data collection. Non-significant lack of fit is an indication of good data sequence fit. The $\mathrm{R}^{2}$ value $=0.99$, adjustable $\mathrm{R}^{2}$ value $=0.98$, The Predicted $\mathrm{R}^{2}$ of 0.9925 is in reasonable agreement with the Adjusted $\mathrm{R}^{2}$ of 0.9964 ; that the difference must be less than 0.2 , Standard deviation 0.1495 for compressive force, a study by (Shelake et al 2018.) also shows that moisture content has significant effect on change in bulk density, true density, the angle of repose, the coefficient of friction and rupture force of turmeric rhizome which was the same in this study. Poornima et al.,2019. Compared turmeric rhizomes at three condition of fresh, boiled and dried conditions which all are effect related to moisture content of the rhizome revealed the significant effect of moisture in all the properties experimented. 
Table 4: ANOVA for selected factorial model for Turmeric rhizome Force holding Capacity (N)

Response 2: Force holding Capacity (N)

Source Sum of Squares Df Mean Square F-value p-value

$\begin{array}{lrrrrrr}\text { Model } & 197.94 & 4 & & 49.49 & 1740.53 & 0.001 \text { Significant } \\ \text { A-Moisture Content } & 196.00 & 2 & & 98.00 & 3446.85 & 0.001 \\ \text { B-Geometric Size } & 1.94 & 2 & & 0.9723 & 34.20 & 0.01 \\ \text { AB } & 0.168 & 4 & 0.0421 & 1.88 & 0.19 \\ \text { Residual } & 0.3696 & 13 & 0.0284 & & \\ \text { Lack of Fit } & 0.1684 & 4 & 0.0421 & 1.88 & 0.1978 \text { not significant } \\ \text { Pure Error } & 0.2012 & 9 & 0.0224 & & \\ \text { Cor Total } & 198.31 & 17 & & & \end{array}$

Table 5: ANOVA for Selected Factorial Model for Turmeric Rhizome Strength

Response 3: Strength (MPa)

\section{Source Sum of Squares Df Mean Square F-value p-value}

$\begin{array}{lrrrrl}\text { Model } & 1.851 \mathrm{E}+05 & 4 & 46280.63 & 2829.97 & 0.001 \text { Significant } \\ \text { A-Moisture Content } & 1.834 \mathrm{E}+05 & 2 & 91676.98 & 5605.88 & 0.012 \\ \text { B-Geometric Size } & 1768.56 & 2 & 884.28 & 54.07 & 0.015 \\ \text { AB } & 67.8 & 4 & 16.77 & 1.04 & 0.439 \\ \text { Residual } & 212.60 & 13 & 16.35 & & \\ \text { Lack of Fit } & 67.08 & 4 & 16.77 & 1.04 & 0.4394 \text { not significant } \\ \text { Pure Error } & 145.52 & 9 & 16.17 & & \\ \text { Cor Total } & 1.853 \mathrm{E}+05 & 17 & & & \end{array}$


Design-Expert@ Software

Factor Coding: Actual

\section{Compressive max force $(\mathrm{N})$}

- Design points above predicted value

Design points below predicted value

$\mathrm{X} 1$ = A: Moisture Content

$\mathrm{X} 2$ = B: Geometric Size

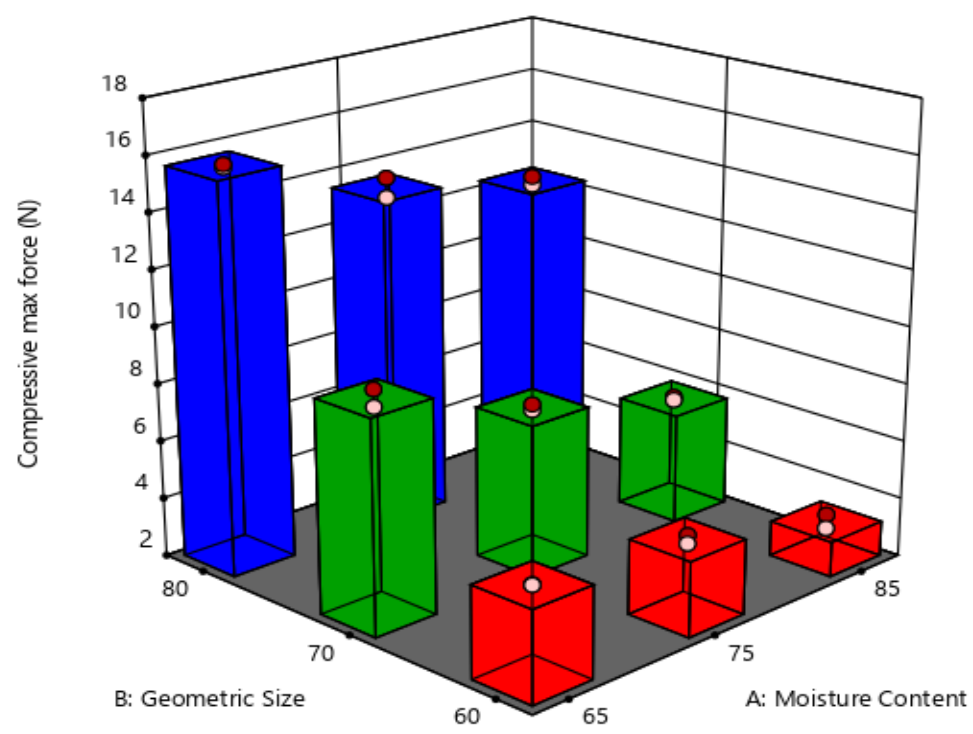

Figure 4 : Effect of Moisture content and Geometric size on Compressive Max Force (N)

Design-Expert ${ }^{\circledR}$ Software

Factor Coding: Actual

\section{Strength (MPa)}

Design points above predicted value

Design points below predicted value

$\mathrm{X} 1$ = A: Moisture Content

$\mathrm{X} 2$ = B: Geometric Size

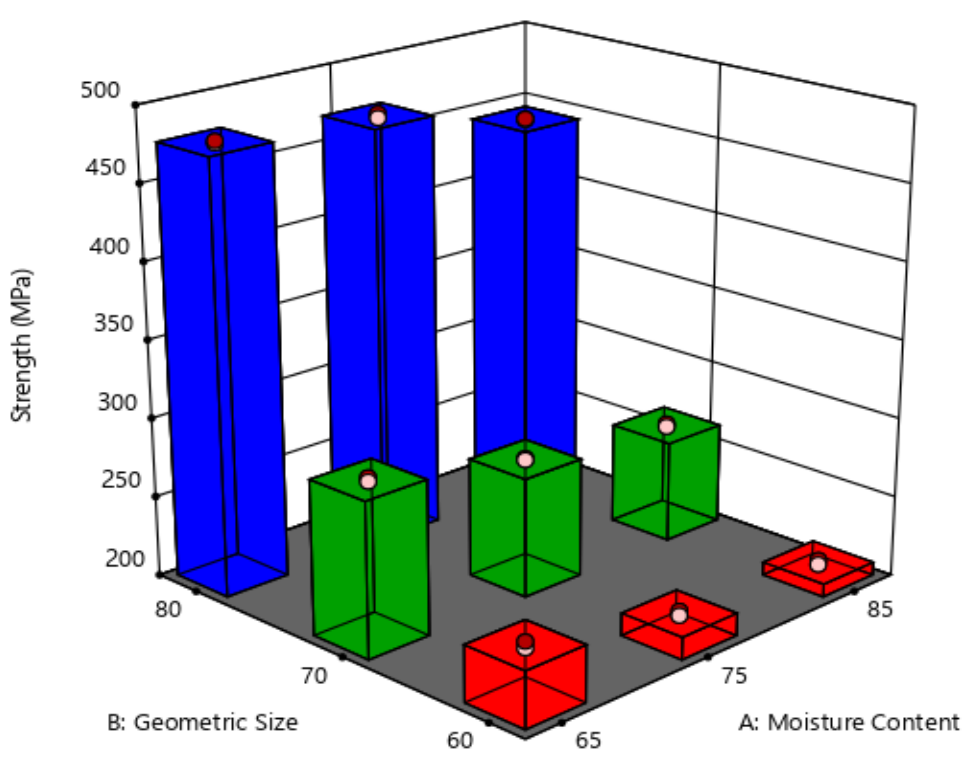

Figure 5 : Effect of Moisture content and Geometric size on Max strength (MPa) 
Design-Expert@ Software

Factor Coding: Actual

Force holding Capacity (N)

- Design points above predicted value

Design points below predicted value

$\mathrm{X} 1$ = A: Moisture Content X2 = B: Geometric Size

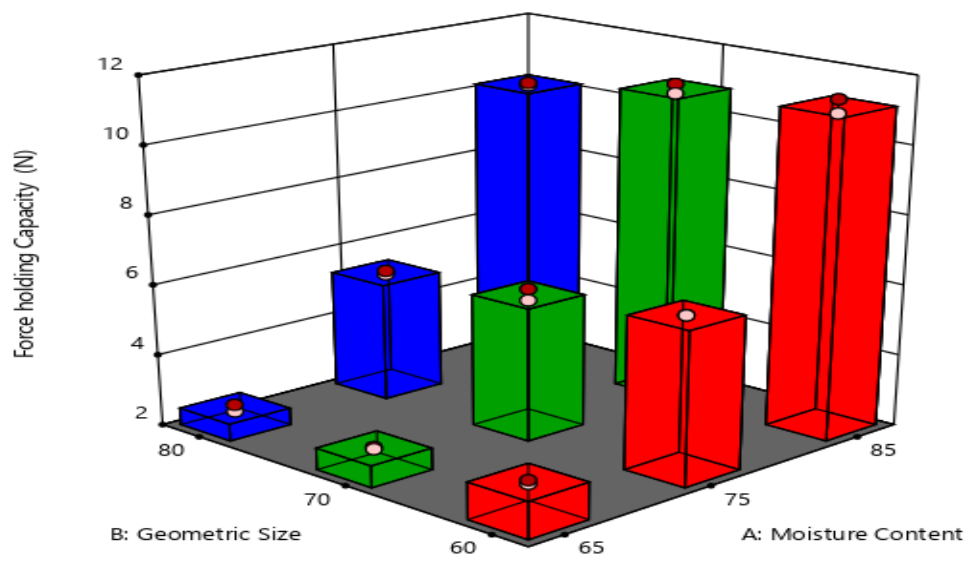

Figure 6: Effect of Moisture Content and Geometric size on Force Holding Capacity (N)

\section{Conclusion:}

The mechanical properties of the rhizomes such as Compressive Force (N), Max Strength (MPa), Force Holding Capacity $(\mathrm{N})$. at different geometric size and moisture content were determined. The statistical analysis of the data collected shows the two factors has significant effect on the tested properties at $\mathrm{P} \leq 0.05$ with lack of fit not significant for all the test. Turmeric rhizomes with 70 to $80 \% \mathrm{MC}_{\mathrm{wb}}$ is suggested for range to be use for mechanical properties affected machines and equipment in the bases of result in this study.

\section{REFERENCE}

Akram M, Shahab U, Ahmed A, Khan U, Hannan A, Mohiuddin E. Asif M. (2010) Curcuma longa and curcumin: a review. Romanian Journal of Biology-Plant Biology. volume 55 issue 2 :pages 65-70.

Akbarnejad, A., Azadbakht, M., \& Asghari, A. (2017). Studies of the selected mechanical properties of banana (Cavendish Var.). International Journal of Fruit Science, 17(1), 93-101. https://doi.org/10.1080/1553 8362.2016.1259083. 
Chattopadhyay, I., Biswas, K., Bandyopadhyay, U. and Banjerjee, RK. (2004). Turmeric and Curcumin: Biological actions and Medical Applications. Curr Science, 87:44-53.

Chukwu O. and Sunmonu M.O. (2010). Determination of Selected Engineering Properties of Cowpea (Vignaunguiculata) Related to Design of (2010). Processing Machines. International Journal of Engineering and Technology. Vol.2 (6), 2010, 373-378.

Ercisli S, Orhan E, Ozdemir O and Sengul M (2007). The genotypic effects on the chemical composition and antioxidant activity of sea buckthorn (Hippophaerhamnoides L.) berries grown in Turkey. Scientia Hoticulturae, 115(1): 27-33.

Fadavi A, Barzegar M, Azizi MH and Bayat M (2005). Physicochemical composition of ten Turmeric Rhizome cultivars (Punica granatum L.) grown in Iran. Food Science and Technology International, 11: 113-119.

Govindarajan, V.S. (1980). Turmeric-Chemistry, technology and quality. Critical Reviews in Food Science and Nutrition, 12(3): 199-301.

Gursoy S. and Guzel E. (2010). Determination of Physical Properties of Some Agricultural Grains. Research Journal of Applied Science, Engineering and Technology. 2(5):492-8.

Kayode Azeez, Abideen Abolanle and Kayode Omowumi Titilola2 (2019)An overview of the therapeutic functions of ginger Journal of Drugs and Pharmaceutical Science Volume 3(2), pages20-23,June ArticleNumber:BB4FE06B1https://doi.org/10.31248/JDPS2019.020 http:/ /Www. integrityresjournals.org/journal/JDPS Review.

Muogbo P.C, and Obasa P. A, (2020) Determination of strength and physical properties of turmeric rhizome at different geometric size. International journal of Advances in Engineering and Management (IJAEM) ISSN: 2395-5252 Volume 2, Issue 4, pp: 523-528 www.ijaem.net.

Shelake P. S., Sagar Yadav, M. L. Jadhav and M. N. Dabhi (2018). Effect of Moisture Content on Physical and Mechanical Properties of Turmeric (Curcuma longa) Rhizome. Current Journal of Applied Science and Technology 30(5): 1-7, 2018; Article no. CJAST.44672 ISSN: 2457-1024.

Olojede, A.O. (2000). IITA/NRCRI collaborative Germplasm and Data Collection on root and tuber crops in Nigeria NRCRI Animal report.

Poornima DS, Ganapathy S and Surendrakumar A (2019) Comparison of physical properties of turmeric rhizomes at fresh, boiled and dried conditions. Journal of Pharmacognosy and Phytochemistry Volume 8 Issues 6: pages 44-48. 